\title{
An Improved Model to Calculate Pullback Force of Trenchless Horizontal Directional Drilling Pipeline
}

\author{
Xiao-qiang Liang, ${ }^{1,2,3}$ Da Hu $\mathbb{D}^{1,},{ }^{1,2,3}$ Yong-suo Li $\left(\mathbb{D},{ }^{1}\right.$ Xian Yang, Lei Jiang, ${ }^{4}$ \\ and Yun-yi Zhang $\mathbb{D}^{1,2,3}$ \\ ${ }^{1}$ Hunan Engineering Research Center of Structural Safety and Disaster Prevention for Urban Underground Infrastructure, \\ Hunan City University, Yiyang 413000, China \\ ${ }^{2}$ School of Civil Engineering, Hunan City University, Yiyang 413000, China \\ ${ }^{3}$ Key Laboratory of Metallogenic Prediction of Nonferrous Metals and Geological Environment Monitoring, \\ Ministry of Education, Central South University, Changsha 410083, China \\ ${ }^{4}$ School of Resource, Environment and Safety Engineering, Hunan University of Science and Technology, Xiangtan, \\ Hunan 411201, China \\ ${ }^{5}$ Changsha Metro Group Co., Ltd., Changsha 410007, China
}

Correspondence should be addressed to Da Hu; huda@hncu.edu.cn

Received 6 August 2021; Revised 23 December 2021; Accepted 3 January 2022; Published 20 January 2022

Academic Editor: Afaq Ahmad

Copyright (c) 2022 Xiao-qiang Liang et al. This is an open access article distributed under the Creative Commons Attribution License, which permits unrestricted use, distribution, and reproduction in any medium, provided the original work is properly cited.

\begin{abstract}
In the pullback operation of horizontal directional drilling pipeline crossing, the existing calculation and prediction models of pullback force are relatively simple. Each pullback force maze greatly simplifies the wellbore trajectory and fails to make a detailed analysis of the pipeline stress and external resistance when the pipeline is pulled back in each characteristic trajectory area. The factors considered are relatively simple. Therefore, it is necessary to improve the calculation method of pullback force. This paper aims to establish an improved model, enhancing the earth pressure calculation method of unloading arch and winch calculation method, and carries out an example calculation of the improved formula. Therefore, it is necessary to study the pullback process of horizontal directional drilling pipeline. Firstly, this paper analyzes the calculation method of pullback force in horizontal directional drilling; studies the calculation formula and principle of common pullback force through examples; obtains the advantages, disadvantages, and applicable scope of different formulas; and improves the calculation model of pullback force and step resistance. The numerical simulation of the step crossing process is carried out, and the variation law of local stress and strain of the pipeline and relevant conclusions are obtained. The results show that the estimates of the winch calculation method are close to the actual pullback load of the project. The earth pressure calculation method of the unloading arch and the winch calculation method are improved, and a more stable and reliable calculation formula is obtained, which provides more valuable calculation data for the actual project. In the process of pullback, the pipeline will encounter step resistance after passing through the soft and hard staggered stratum, which will suddenly increase the increment of pipeline pullback force and lead to engineering accidents. If the pullback load suddenly increases and then decreases, it may encounter similar pipeline collision accidents. At the same time, emergency measures can be taken to prevent the crossing accident and ensure the safe pullback of the pipeline.
\end{abstract}

\section{Introduction}

With the continuous development of the social economy, people's awareness of civilization and environmental protection is becoming stronger and stronger, and the requirements for a living environment are also higher [1]. In order to reduce the environmental protection problems caused by excavation when laying underground pipelines, new technology is urgently needed to meet the needs of people. Horizontal directional drilling (HDD) is to drill a pilot hole of a calibre size according to the horizontal directional drilling rig's design line and crossing curve. Then, 
the drill bit is changed to a larger reamer to perform more than one pullback reaming process. When the hole diameter meets the design requirements, the full-length pipeline is finally towed back and laid. Furthermore, most of the longdistance crossing projects adopt the dual-drilling rig docking method for pilot hole construction [2-4]. As a new construction technology, HDD technology includes high construction precision, fast speed, and negligible environmental impact. Therefore, HDD technology has gradually received more and more attention [5]. HDD technology is a largescale project combining multiple technologies, equipment, and disciplines. All aspects of the construction are linked together, and problems in one of the links will increase the cost of the project or affect the progress of the whole project [6]. HDD technology was first used in oil drilling and gradually combined with infrastructure construction and water well industry. Nowadays, it is widely used in the construction of oil and gas, municipal pipelines, etc. [7]. At present, HDD technology is also commonly used in ground source heat pump and gas layer drilling, and the application effect is good [8]. Compared with other nonexcavation pipeline technologies, HDD technology has more advantages, such as low construction cost, high efficiency, and minor surface disturbance. As a result, it has received more and more attention and has achieved better social and economic benefits [9]. As a branch of trenchless construction technology, horizontal directional drilling crossing technology has not been used in pipeline construction for a long time, but with the unremitting efforts of the majority of scientific researchers and engineers, it has made great progress since it was introduced into China in the 1970s. The construction of ground obstacles such as buildings is being widely used, and remarkable achievements have been made. Because of the outstanding advantages and mature technology of horizontal directional drilling, its application scope is expanding. Nowadays, it is used not only in the field of non-open-ended pipeline laying, but also in the fields of geology, metallurgy, petroleum, etc., and it is used in special underground space occasions like exploration and resource development of two underground sites. At present, the research on horizontal directional drilling technology has reached a certain extent. It can not only develop small- and medium-sized drilling machines produced abroad, but also expand the application field of this technology. Now, directional drilling technology not only has been applied to the laying of pipelines under complex conditions, but also can be applied to exploration and information collection in underground dangerous areas, such as laying military optical cables crossing busy roads or rivers, and automatic collection of soil data in the tunnel area after underground nuclear test. The research of horizontal directional drilling involves the research of various fields, including the research of pipeline back drag force calculation and the research of pipeline step crossing and the local stress deformation of the pipeline during the process of back drag.

Nowadays, China is in a rapid development stage, and there are more and more large-scale infrastructure projects, which will significantly promote the wide application of HDD technology. Simultaneously, the development of orientation, machinery, and computer technology also provides theoretical support for the application of HDD $[10,11]$. In 2010, Chehab and Moore also put forward the mathematical method for calculating the pullback force. They considered the winch effect and the development of the pipeline. Many domestic scholars have also studied the calculation method of pullback force. For example, Hu Shilei put forward a new calculation model of separation in 2012. He not only considered the pipe bending, but also split the bending, considered the situation of pipes under different bending types and strengths, and gave calculation formulas, respectively. Through example verification, the value of pullback force calculated by the new method is more accurate [12]. At present, there is a lack of basic research on the design value of horizontal directional drilling hole/pipe diameter ratio at home and abroad for a long time, and engineering practice depends on some empirical data with a large value range for a long time. Some studies have proposed the calculation method of the bending strength of the curve section, and it is considered that the reasonable limit bending strength of the hole body can be determined only by analyzing and comparing four aspects of the limit bending strength, namely, the limit bending strength of the hole body through which the bottom hole dynamic drilling tool passes smoothly, the limit bending strength of the hole body for safe operation of the drill string, the limit bending strength of the hole body for safe operation of the pipeline, and the limit bending strength of the hole body with the lowest deviation cost per degree [13]. The pipe diameter ratio is the ratio of the diameter of the guide hole to the diameter of the pullback pipe. According to the proposed pullback load prediction method, some scholars analyzed the influence of pipe diameter ratio on the pullback load. When the value is less than 1.5, the change of pipe diameter ratio has a great impact on the pullback load, and when the value is greater than 1.7, the change of pipe diameter ratio has little impact on the calculation results of pullback load [5]. It can be seen that the pipe diameter ratio has an important influence on the pullback load. Therefore, this study analyzes the calculation method of the pullback force of horizontal directional drilling, aiming to improve the calculation models of the backdrop force and the resistance of the step crossing via a case study. To facilitate full understanding of the HDD mechanism, numerical simulation of the step hole crossing is performed. Our research helps to ensure that the directional crossing process can adjust the construction process in time according to the actual situation of the site construction, avoid crossing accidents, and effectively reduce the construction cost and risk.

\section{Establishment of an Improved Model to Calculate Pullback Force of HDD}

2.1. Calculation and Analysis of Pullback Force in HDD. The pullback force of HDD is complex and consists of knowledge in many disciplines, such as geotechnical, material, fluid, and other mechanics. Among these, the most crucial factor is the cross-sectional size when pulling back the drill. To complete the pipeline crossing smoothly, all the 
resistance in the pulling back process needs to be overcome. There are basically four methods to calculate the HDD's pullback force based on the GB50423 standard, the unloading arch earth pressure, the net buoyancy, and the winch effect [14]. Among these calculations, the GB50423 standard provides a straightforward model, mainly considering the buoyancy of the pipeline in the drilling, as shown in the following equation:

$$
F_{P}=\pi L f g\left[\frac{D_{2}}{4} \rho_{m}-\rho_{s}(D-\delta)\right] \times 10^{3}+k_{v} g \pi D L .
$$

In (1), $F_{\mathrm{P}}$ is the pulling force of the drilling rig with the unit of $\mathrm{N} ; L$ is the length of the pipeline with the unit of $m$; $\rho \mathrm{m}$ is the mud density with the unit of $\mathrm{kg} / \mathrm{m}^{3} ; f$ is the friction factor, being between 0.2 and $0.5 ; g$ is the acceleration of gravity with the unit of $\mathrm{m} / \mathrm{s}^{2} ; D$ is the outer diameter of the pipeline with the unit of $m ; \delta$ is the thick wall of the pipeline with the unit of $m$; and $k_{v}$ is the viscosity coefficient, being between 0.01 and 0.05 . Note that $1.2 \sim 2.5$ times of the calculation result of the formula is the final calculation result of the drilling rig. Nonetheless, (1) is an idealized model without full consideration of all influential factors.

The 2nd method is to obtain the unloading arch's earth pressure, which mainly analyzes the influence of the unloading arch above the pipeline on the pipeline's total pullback load, without considering the mud buoyancy inside the borehole. This calculation is given in the following equation:

$$
T_{\max }=\left[2 P\left(1+K_{\alpha}\right)+P_{0}\right] f_{e} L .
$$

In (2), $T_{\max }$ is the maximum drag force with the unit of $\mathrm{kN}$; $P$ is the earth pressure per unit length with the unit of $\mathrm{kN} ; K_{\alpha}$ is the earth pressure factor, taking $0.3 ; P_{0}$ is the

gravity per unit pipe with the unit of $\mathrm{kN} / \mathrm{m} ; f_{e}$ is the friction factor between the pipe and the borehole, being between 0.1 and $0.35 ; L$ is the total length of the pipe with the unit of $m ; g$ is the gravity acceleration with the unit of $\mathrm{m} / \mathrm{s}^{2}$; and $k_{v}$ is the viscosity coefficient [0.01-0.05]. Considering the drilling quality factors, the geotechnical thickness $h$ (unit: $\mathrm{m}$ ) and the vertical earth pressure (unit: $\mathrm{kN} / \mathrm{m}$ ) of the pipe top are shown as follows:

$$
\begin{aligned}
h & =\frac{D_{e}[1+t g(\pi / 4-\phi / 2)]}{2 f_{k p}}, \\
P_{v} & =\frac{v_{e} D_{0} h}{\lambda} \\
& =\frac{v_{e} D_{0} D_{e}[1+t g(\pi / 4-\phi / 2)]}{2 f_{k p} \lambda} .
\end{aligned}
$$

In (3) and (4), $D_{e}$ is the borehole size with the unit of $m ; \lambda$ is the borehole mass coefficient, being between 20 and $35 ; \phi$ is the rock and soil internal friction angle: $\phi=\operatorname{arctg} f_{k p} ; f_{k p}$ is the rock and soil coefficient, being 0.3 ; $v_{e}$ is the rock and soil bulk density with the unit of $\mathrm{kN} / \mathrm{m}^{3} ; D_{0}$ is the outer pipe diameter with the unit of $m$; and $h$ is the top rock and soil height with the unit of $m$. Safe pullback during construction usually means to reduce the friction force between the pipe and the hole wall and to keep the size ratio of the borehole and the pipe between 1.2 and 1.6, so the lateral earth pressure $P_{k}$ (unit: $\mathrm{kN} / \mathrm{m}$ ) is calculated during the pulling back process, as follows:

$$
P_{h}=P_{v} \operatorname{tg}^{2}\left(\frac{\pi}{4}+\frac{\pi}{2}\right)
$$

Substituting (3) into (5) and $P=P_{v}+P_{h}$ into (2), we have

$$
T_{\max }=f_{e} L\left\{2\left(1+K_{\alpha}\right)\left[\frac{v_{e} D_{0} D_{e}[1+t g(\pi / 4-\phi / 2)]}{2 f_{k p} \lambda}+P_{v} t g^{2}(\pi / 4+\pi / 2)\right]+P_{0}\right\} .
$$

Although the earth pressure calculation of the unloading arch is relatively safe, the calculation process is complex and needs to meet too many conditions.

The 3rd method is to obtain the net buoyancy, which considers the influence of gravity and mud buoyancy on the pipeline, as shown in the following equation:

$$
T_{\max }=\left|P_{0}-P_{f}\right| f_{m} L
$$

In (7), $P_{0}$ is the weight per unit length of pipe with the unit of $\mathrm{kN} / \mathrm{m} ; P_{f}$ is the buoyancy in the drilling hole per unit length of pipe with the unit of $\mathrm{kN} / \mathrm{m}$; and $f_{m}$ is the comprehensive friction factor, being between 0.5 and 0.8 . If we neglect the thickness and weight of the outer coating of the rigid pipe, we can obtain

$$
\left|P_{0}-P_{f}\right|=\frac{\pi}{4}\left|4\left(D_{0}-\delta\right) \delta \gamma_{s}-D_{0}^{2} \gamma_{m}\right|
$$

In (8), $\delta$ is the wall thickness of the crossing pipe with the unit of $m ; \gamma_{s}$ is the weight of steel, usually $78.5 \mathrm{kN} / \mathrm{m}^{3}$; and $\gamma_{m}$ is the volume weight of slurry soil mixture in the hole, usually 11 to $12 \mathrm{kN} / \mathrm{m}^{3}$. By substituting (8) into (7), the maximum pullback force of the net buoyancy calculation is obtained as follows:

$$
T_{\max }=\frac{\pi}{4}\left|4\left(D_{0}-\delta\right) \delta \gamma_{s}-D_{0}^{2} \gamma_{m}\right| f_{m} L .
$$

However, the above calculation is still idealized, as the winch effect caused by the bending section at both ends is not considered, so the range of the friction coefficient is broad. Therefore, the 4 th method considering the winch effect is developed, mainly regarding the pipeline as a flexible steel cable wound on the huge drum, so the pullback force (unit: $\mathrm{kN}$ ) of the horizontal pipeline is calculated from the ground surface. 


$$
F_{s}=\mu P_{B} L .
$$

In (10), $\mu$ is the friction factor of the fluid between the pipe and the ground or in the borehole; $P_{B}$ is the weight of the unit pipe length on the ground or the net buoyancy in the borehole with the unit of $\mathrm{kN} / \mathrm{m}$. If the radius of the bending section reaches a particularly large value, the calculation of the pullback force $T_{C}$ (unit: $\mathrm{kN}$ ) of the vertical section or the horizontal section of the pipeline when considering the winch effect is shown in the following equation:

$$
T_{C}=e^{\mu \theta}\left(\mu P_{B} L\right)
$$

In (11), $\theta$ is the pipe wrap angle and $\mu$ is the friction factor between mud and pipe. Considering the resistance caused by the mud during the pipeline backhauling, the backhauling head is regarded as the base point, and the following equation can be derived from (10) and (11).

$$
\left\{\begin{array}{l}
F_{A}=e^{\mu_{\alpha} \alpha}\left(\mu_{\alpha} P_{0}\left(L_{1}+L_{2}+L_{3}+L_{4}\right)\right), \\
F_{B}=e^{\mu_{\alpha} \alpha}\left(F_{A}+T_{h}+\mu_{b}\left|P_{0}-P_{f}\right| L_{2}-\left(P_{0}-P_{f}\right) H_{1}-e^{\mu_{\alpha} \alpha}\left(\mu_{\alpha} P_{0} L_{2}\right)\right), \\
F_{C}=F_{B}+T_{h}+\mu_{b}\left|P_{0}-P_{f}\right| L_{3}-e^{\left(\mu_{\alpha}+\mu_{b}\right) \alpha}\left(\mu_{\alpha} P_{0} L_{3}\right), \\
F_{D}=e^{\mu_{\alpha} \beta}\left(F_{C}+T_{h}+\mu_{b}\left|P_{0}-P_{f}\right| L_{4}+\left(P_{0}-P_{f}\right) H_{2}-e^{\left(\mu_{\alpha}+\mu_{b}\right) \alpha}\left(\mu_{\alpha} P_{0} L_{4}\right)\right) .
\end{array}\right.
$$

In $\quad(12), \quad T_{h}=\pi / 8 \rho\left(D_{e}^{2}-D_{o}^{2}\right), \quad\left|P_{0}-P_{f}\right|=\pi / 4 g \mid 4$ $\left(D_{0}-\delta\right) \delta \gamma_{s}-D_{0}^{2} \gamma_{m} \mid . F_{A}, F_{B}, F_{C}$, and $F_{D}$, respectively, represent the pullback forces when the pipeline is pulled back to the entry point $A$, the end bending point $B$, the end bending point $\mathrm{C}$, and the exit point $D$; $\mathrm{P}$ represents the mud pressure with the unit of $\mathrm{kN} / \mathrm{m}^{3} ; T_{h}$ represents the movement resistance: $T_{h}=\pi / 8 q\left(D_{e}^{2}-D_{0}^{2}\right)$, with the unit of kN; $L_{1}, L_{2}, L_{3}$, and $L_{4}$, respectively, represent the additional length of the pipeline, the horizontal pullback length from $\mathrm{A}$ to $B$, the length from $B$ to $C$ in the middle horizontal section, and the horizontal pullback length from $\mathrm{C}$ to $D$, with the unit of all these lengths being $m ; \mu_{\alpha}$ and $\mu_{b}$ represent friction factors of the ground section $(0.2-0.3)$ and the hole (0.15-0.25); $\mathrm{H}_{1}$ and $\mathrm{H}_{2}$, respectively, represent the maximum buried depths of the ground end and the excavation end; and $\alpha$ and $\beta$, respectively, represent the entry angle and exit angle.

It can be seen from the above equation that $F_{D}>F_{C}>$ $F_{B}>F_{A}$ indicating that when the pipe is pulled into the expanded borehole, the pullback force increases slowly. Finally, when it is pulled to point $D$, the force reaches the maximum, agreeing with the actual situation.

2.2. Case Studies. The calculation example of pullback force conducts the case study. First, the engineering parameters are determined according to the actual situation of the project. According to ASTM regulations (0.12-0.2) and the existing construction properties, the friction coefficient between the ground and the pipeline is set to be 0.15 , the mud viscosity resistance is 0.25 , and the friction coefficient in the borehole is 0.25 [15]. This study mainly analyzes three engineering cases: $\mathrm{AA}, \mathrm{BB}$, and $\mathrm{CC}$, respectively. Due to the limited space in this paper, only the calculation process of $\mathrm{AA}$ is introduced in detail. AA is refined oil pipeline project, as shown in Figure 1.
The total length of AA crossing line of the project is $1984 \mathrm{~m}$. The length of the downward horizontal section, ground bending area, middle horizontal section, ground bending section, and upward horizontal section is $256 \mathrm{~m}$, $80 \mathrm{~m}, 1.283 \mathrm{~m}, 70 \mathrm{~m}$, and $295 \mathrm{~m}$, respectively. The outer diameter $D_{0}$ of the pipeline used is $0.61 \mathrm{~m}$, the wall thickness $d$ is $0.127 \mathrm{~m}$, and the reaming diameter $D_{\mathrm{e}}$ is $0.65 \mathrm{~m}$. The entry angle $a$ and the excavation angle $\beta$ are $16^{\circ}$ and $14^{\circ}$, respectively, and the crossing depth $H_{1}=H_{2}=73.5 \mathrm{~m}$.

According to the formula of the pullback force of the drilling rig, the above data are substituted into (1) to get $F_{\mathrm{P}}=823.6 \mathrm{kN}$. Considering that the pullback force of the drilling rig is twice $F_{\mathrm{P}}$ in this study, $F=F_{\mathrm{P}} \times 2=1647.2 \mathrm{kN}$. Furthermore, by the method of unloading the arch soil pressure, the data is substituted into (6), so $T_{\max }=2261 \mathrm{kN}$, where $f_{\mathrm{e}}=0.25, D_{0}=0.61 \mathrm{~m}, D_{\mathrm{e}}=0.65 \mathrm{~m}, L=1984 \mathrm{~m}$, $v_{\mathrm{e}}=24 \mathrm{kN} / \mathrm{m}, K_{\alpha}=0.3, f_{\mathrm{kp}}=0.8, \lambda=40, P_{0}=1.949 \mathrm{kN} / \mathrm{m}$. Moreover, through the net buoyancy method, the data is substituted into (9) to obtain $T_{\max }=3544 \mathrm{kN}$, where $f_{\mathrm{m}}=0.65, \quad r_{\mathrm{m}}=11.5, D_{0}=0.61 \mathrm{~m}, \delta=0.127 \mathrm{~m}, \quad \gamma_{\mathrm{s}}=78 \mathrm{kN}$, $\gamma_{\mathrm{m}}=11 \mathrm{kN} / \mathrm{m} 3, L=1984 \mathrm{~m}$. Finally, by substituting the data into (12) according to winch effect, the maximum pullback force $T_{\max }=718 \mathrm{kN}$, where $\mu_{\alpha}=0.15, \mu_{\mathrm{b}}=0.25, r_{\mathrm{m}}=11.5$, $\alpha=14^{\circ}, \quad \beta=16^{\circ}, L_{1}=14.4 \mathrm{~m}, L_{2}=287 \mathrm{~m}, L_{3}=1356 \mathrm{~m}$, $L_{4}=317 \mathrm{~m}$. Similarly, the pullback forces of the other two projects could be obtained. All these forces, together with the corresponding measured pullback forces, are listed and compared in Table 1.

It can be shown from Table 1 that the pullback force is the result of various factors: different geological conditions and equations result in different deviations in estimation. Therefore, the calculation method should be determined according to the specific geological conditions. It is interesting to see that among the above four methods, the winch calculation method gives the closest estimate of the force compared to the actual one. 


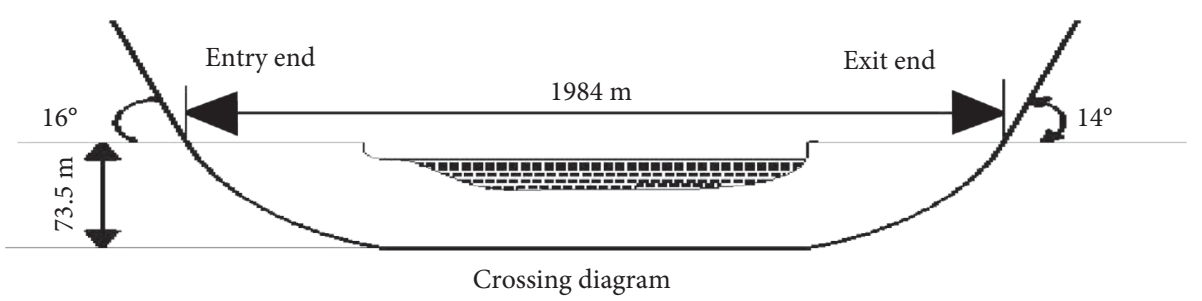

FIgURE 1: Cross section of product oil pipeline crossing project.

TABLE 1: Comparison of pullback forces in three cases.

\begin{tabular}{lccc}
\hline \multirow{2}{*}{ Calculation method } & \multicolumn{3}{c}{ Engineering } \\
& AA & BB & CC \\
\hline Unloading arch earth pressure method $(\mathrm{kN})$ & 2261 & 1221 & 923 \\
Winch calculation method $(\mathrm{kN})$ & 718 & 693 & 997 \\
Actual pullback force $(\mathrm{kN})$ & 810 & 997 & 681 \\
\hline
\end{tabular}

\subsection{Establishment of an Improved Model for Pullback Force} Calculation. In directional drilling engineering, drilling cuttings are flushed away by mud, improving the stability of hole wall [16]. Therefore, the method that considers the effect of mud on the buoyancy is supposed to be more suitable for the pullback force calculation. Therefore, (2) about the method of unloading arch earth pressure is improved as follows:

$$
T_{\text {max }}=\left[2 P\left(1+K_{\alpha}\right)+\left(P_{0}-P_{f}\right)\right] f_{e} L .
$$

By substituting $P_{v}=v_{e} D_{0} h / \lambda=v_{e} D_{0} D_{e}[1+\operatorname{tg}(\pi / 4-$ $\phi / 2)] / 2 f_{k p} \lambda, P_{h}=P_{v} \operatorname{tg}^{2}(\pi / 4-\pi / 2)$, and $P=P_{v}+P_{h}$ into (13), the optimized equation based on unloading arch soil and net buoyancy is

$$
T_{\max }=f_{e} L\left\{\frac{v_{e} D_{0} D_{e}[1+\operatorname{tg}(\pi / 4-\phi / 2)]\left[1+\operatorname{tg}^{2}(\pi / 4+\phi / 2)\right]\left(1+k_{\alpha}\right)}{f_{k p} \lambda}+\left(P_{0}-P_{f}\right)\right\} .
$$

This is the improved calculation formula based on unloading arch soil and net buoyancy calculation method. In addition, considering the correlation between parameters and that some parameters change little, (14) can be simplified to the equations below, being straightforward for practical purposes:

$$
\begin{array}{r}
T_{\max }=f_{e} L\left(4 D_{0} D_{e}+\left(P_{0}-P_{f}\right)\right), \\
\left|P_{0}-P_{f}\right|=\frac{\pi}{4}\left|4\left(D_{0}-\delta\right) \delta \gamma_{s}-D_{0}^{2} \gamma_{m}\right| .
\end{array}
$$

On the other hand, as shown previously, the calculation based on winch effect consideration gives best estimate of the force (see Table 1). Nevertheless, it can be seen from (12) that the winch calculation method is unreasonable both in the equation and the actual working condition. In fact, it can be seen from the calculation results and the actual engineering that the influence of the mud flow resistance on the back drag force of the pipeline is very small, so the calculation of this force has little practical significance. In the estimation stage of the pullback force, its size can be ignored completely, which has little influence on the calculation results. In addition, the earth pressure on the top of the pipe is also considered in the formula, but this method is too rough and far from the actual working condition. The calculation method of earth pressure above the pipe top in the earth pressure calculation method of unloading arch introduced above is relatively mature in the theory of soil mechanics. So, this method can be applied in the winch calculation to calculate the earth pressure above the pipe top. According to the unloading arch earth pressure method,

$$
F=2 P\left(1+K_{\alpha}\right) f_{e} L .
$$

Among them, $P=P_{v}+P_{h}, \quad h=\operatorname{De}[1+\operatorname{tg} \quad(\pi / 4-$ $\phi / 2)] / 2 f_{k p}, P_{v}=v_{e} D_{0} h / \lambda=v_{e} D_{0} D_{e}(\pi / 4-\phi / 2) / 2 f_{k p} \lambda$, and $P_{h}=P_{v} \operatorname{tg}(\pi / 4-\phi / 2)$. After substituting (17), the following equation is obtained.

$$
F=\frac{v_{e} D_{0} D_{e}[1+t g(\pi / 4-\phi / 2)]\left[1+t g^{2}(\pi / 4-\phi / 2)\right]\left(1+K_{\alpha}\right) f_{e} L}{f_{k p} \lambda} .
$$

Considering that there is a certain internal relationship between some parameters and that some parameters change little, (18) can be simplified to the following equation:

$$
F=4 f_{e} L D_{0} D_{e}
$$

Therefore, the improved calculation method is shown as follows: 


$$
\left\{\begin{array}{l}
T_{B}=e^{\mu_{a} \alpha}\left(T_{A}+\mu_{b}\left|P_{0}-P_{f}\right| L_{2}+4 D_{0} D_{e} \mu_{b} L_{2}-e^{\mu_{a} \alpha}\left(\mu_{a} P_{0} L_{2}\right)\right), \\
T_{C}=e^{\mu_{b} \alpha}\left(T_{B}+\mu_{b}\left|P_{0}-P_{f}\right| L_{3}+4 D_{0} D_{e} \mu_{b} L_{3}-e^{\left(\mu_{a}+\mu_{b}\right) \alpha}\left(\mu_{a} P_{0} L_{3}\right)\right), \\
T_{D}=e^{\mu_{b} \alpha}\left(T_{C}+\mu_{b}\left|P_{0}-P_{f}\right| L_{4}+4 D_{0} D_{e} \mu_{b} L_{4}-e^{\left(\mu_{a}+\mu_{b}\right) \alpha}\left(\mu_{a} P_{0} L_{4}\right)\right) .
\end{array}\right.
$$

$T_{\mathrm{B}}$ is the pullback force $(\mathrm{kN})$ when the pipe is pulled back to the final bending point $B$ at the end of entering soil, $T_{\mathrm{C}}$ is the pullback force $(\mathrm{kN})$ when the pipe is pulled back to the bending point $\mathrm{C}$ at the earth end, and $T_{\mathrm{D}}$ is the pullback force when the pipe is pulled back to the excavation point $d$ $(\mathrm{kN})$. The improved equation is applied to calculate the AA, $\mathrm{BB}$, and $\mathrm{CC}$ of the project. The calculation results are shown in Table 2. Compared with Table 1, it can be seen that the improved model has more stability and regularity. The improved calculation results are larger than the actual pullback force, more regular, more in line with the actual situation, and consistent with the actual working conditions.

\section{Numerical Simulation of Pipeline Step Crossing}

3.1. Establishment of a Calculation Model for Step Crossing Resistance. At present, China is in the climax of the development of horizontal directional crossing technology. In many cases, the calculation of pipeline pullback force depends on the empirical value, which is greatly affected by human subjective factors, and the theoretical level is far from meeting the needs of practical engineering. Therefore, it is particularly important to analyze the characteristics of pipeline in the process of crossing, especially the study of pullback load. The back drag load is affected by many factors. At present, the research at home and abroad mainly focuses on the geological conditions, trajectory curvature, mud properties, pipeline materials, and ratio of pipe diameter to hole diameter (hole/pipe ratio) but little on special construction conditions. In order to further improve the pipeline crossing theory, based on the case study of stepped hole crossing project, this section analyzes the influence of step set parameters on pipeline pullback force and pipeline mechanical properties.

The formation of the step is mainly due to the fact that the rock is not cleaned by the cutter when the hole is reamed. The two ends of the reamer have different forces when they pass through the junction of soft and hard formations, which will cause the size of the reaming steps to be different. At present, the most commonly used technology for horizontal directional drilling is back drag reaming. Therefore, when the force on both ends of the reamer is uneven, the influence of different step size on the pullback force is also different [17]. With the occurrence of steps, the actual track of drilling normally differs significantly from the theory.

In order to facilitate the construction of the model, this study assumes that the borehole is stable and that the design is entirely consistent with the actual borehole trajectory. The lithologic soil is rigid support, which will not deform and shift; in addition, the pulling back pipe has uniformity. When the hole wall is intact, the influencing track factors include the friction force $f$ between the hole wall and the pipeline, the pullback force (rig pull force) $T$, the step resistance $f_{\mathrm{t}}$, buoyancy $F$, and gravity $G$. $T$ can be approximately regarded as follows:

$$
T=f+f_{t}+T_{w} .
$$

Since the length of the pipe is much longer than the step length, the contact area of the pipeline passing through the steps is almost unchanged, so $f$ can be ignored and the main influencing factor is $f_{\mathrm{t}}$. The main force between the steps and the pipeline can be regarded as $G, F$, and $T$, where the resultant force of $G$ and $F$ are shown in the following equation:

$$
F_{1}=\frac{\pi}{4}\left|\left(D^{2}-d^{2}\right) \rho_{1}-D^{2} \rho_{2}\right| \cdot g \cdot L .
$$

In (22), $D$ and $d$ are the inner and outer diameters of the pipeline with the unit of $m ; \rho 1$ and $\rho 2$ are the density of the pipeline and mud with the unit of $\mathrm{kg} / \mathrm{m}^{3}$; and $g$ is the acceleration of gravity, i.e., $g=9.8 \mathrm{~m} / \mathrm{s}^{2}$. If the pipeline always keeps balance when crossing the steps, the stress of the pipeline is shown in Figure 2.

According to the force balance principle, the horizontal and vertical calculation methods are shown as follows:

$$
\begin{aligned}
& T=N \cdot \cos \beta+\mu N \cos \alpha+T_{w}, \\
& F=G+\mu N \sin \beta-N \cdot \cos \alpha .
\end{aligned}
$$

Therefore, the step resistance $f_{\mathrm{t}}$ of the front section of the pipeline can be obtained by substituting (21) into (24), as shown in the following:

$$
f_{t}=\frac{\pi}{4} \cdot \frac{1+\mu}{1-\mu} \tan \alpha \cdot\left(D^{2}-d^{2}\right) \rho_{1}-D^{2} \rho_{2} \mid \cdot g .
$$

In (25), the step resistance is positively proportional to $a$ and L. Among them, the height and curvature of the step are closely related to $\alpha$, so it is crucial to consider the influence of the step with different curvatures and heights on the pullback force. Let $\cos =h / r$ and $h$ denote the height of the contact point; thus, the calculation of $f_{\mathrm{t}}$ is as follows:

$$
f_{t}=\frac{\pi}{4} \cdot \frac{1+\mu}{1-\mu} \sqrt{\left|\frac{h^{2}}{r^{2}-h^{2}}\right|}\left|\left(D^{2}-d^{2}\right) \rho_{1}-D^{2} \rho_{2}\right| \cdot g \cdot L .
$$

3.2. Numerical Simulation of Pipeline Crossing with Steps. The rotation of the pipeline during back-pulling is not considered. A symmetrical model is built to reduce the computational expense, and a symmetrical constraint is imposed on the symmetrical plane to avoid rigid body displacement. The model is composed of a pipeline and 
TABLE 2: Table of calculation results after improvement.

\begin{tabular}{lccc}
\hline Computing method & \multicolumn{2}{c}{ Engineering } \\
& AA & BB & CC \\
\hline Unloading arch earth pressure method $(\mathrm{kN})$ & 1566 & 1218 & 695 \\
Winch calculation method $(\mathrm{kN})$ & 857 & 1271 & 997 \\
Actual pullback force $(\mathrm{kN})$ & 695 & 716 & 681 \\
\hline
\end{tabular}

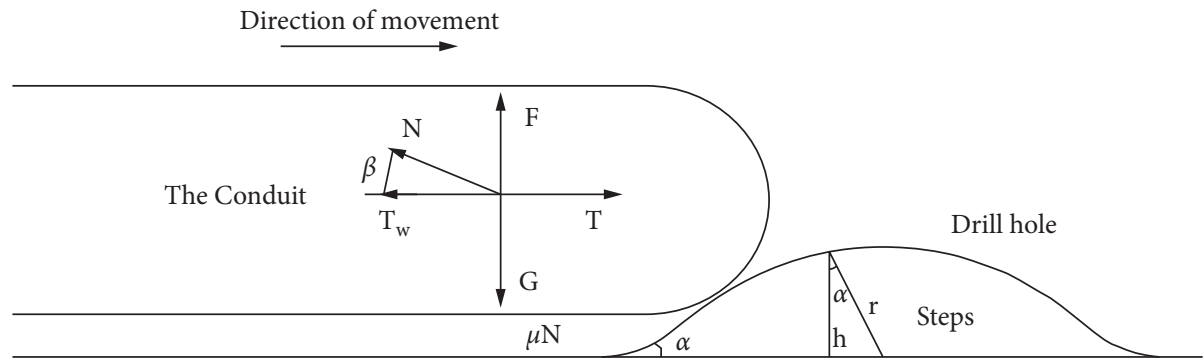

FIgURE 2: Stress analysis of pipeline crossing steps.

geotechnical (with a step) model. When the step height is determined, the higher the contact point between the pipe and the step, the greater the step resistance. When the step height and the contact point height are constant, the step resistance decreases with the increase of step curvature. The above theoretical analysis results lay a theoretical foundation for the simulation results of stepped hole crossing in the later paper and are mutually verified with the simulation results in this paper. The rock length $L$ is $20 \mathrm{~m}$, the height $\mathrm{H}$ is $2 \mathrm{~m}$, and the step height $h$ is $0.1 \mathrm{~m}-0.4 \mathrm{~m}$. The curvature radius $r$ of step and joint is $0.75 \mathrm{~m}$, the radius $R$ is $0.65 \mathrm{~m}$, and the wall thickness $d$ and inner diameter $R$ of the pipe are $0.02 \mathrm{~m}$ and $0.49 \mathrm{~m}$. The pipeline material is $\mathrm{X}-65$, the density in the elastic-plastic constitutive relation is $7800 \mathrm{~kg} / \mathrm{m} 3$, the elastic modulus is $2.1 \mathrm{e} 11 \mathrm{~Pa}$, and the Poisson ratio is 0.3 . The stressstrain data of pipeline in the plastic stage are shown in Table 3.

Drucker-Prager model is applied to the geotechnical plastic model, which is suitable for friction materials such as geotechnical materials [18]. The density, Young's modulus, and Poisson's ratio of geotechnical elastic parameters are $2700 \mathrm{~kg} / \mathrm{m} 3,4.13 \mathrm{e} 10 \mathrm{~Pa}$, and 0.22 respectively; the friction angle $\beta$, strain rate $\mathrm{K}$, and expansion angle $f$ of D-P constitutive model parameters are $44^{\circ}, 0.8$, and $38^{\circ}$, respectively; and the corresponding plastic variables of yield stress in rock hardening parameters under $37.93 \mathrm{MPa}, 38.2 \mathrm{MPa}$, and $38.4 \mathrm{MPa}$ are $0,0.005$, and 0.08 , respectively. The analysis step of stepped hole crossing and the contact attributes between hole wall and pipe are set as follows: analysis step (static general analysis step), contact surface (pipe indication), contact type (surface contact), tangential contact (penalty function), normal contact (linear contact), target surface (hole wall), and friction coefficient (0.2).

The simplified model for the step hole crossing is shown in Figure 3(a), including pipeline and geotechnical models (including the step). The boundary conditions and constraints are set for the model. The model is divided into two grids: structured and unstructured. The results include
TABle 3: Stress-strain data of pipeline in plastic stage.

\begin{tabular}{lccc}
\hline True stress $(\mathrm{MPa})$ & Plastic strain & True stress $(\mathrm{MPa})$ & Plastic strain \\
\hline 418 & 0 & 882 & 0.25 \\
500 & 0.01 & 908 & 0.35 \\
605 & 0.02 & 921 & 0.45 \\
695 & 0.056 & 932 & 0.55 \\
780 & 0.095 & 955 & 0.65 \\
829 & 0.15 & 1 & 1 \\
\hline
\end{tabular}

12076 grids, and the steps are locally encrypted, so much finer meshes are assigned. C3D10 M and C3D8R are used for tetrahedron and hexahedral grid units, respectively, as shown in Figure 3(b).

The model is verified by the engineering pullback load data in [19]. Figure 4(a) shows the recorded results of the engineering load, and Figure 4(b) shows the calculation results of the stepped hole crossing model. Comparing the two figures, we find that the trend of the change curve is basically the same, which reflects the accuracy of the calculation model proposed in this study. Ashkan et al. used the national standard formula to calculate the maximum pullback force, verified the friction coefficient and viscous force coefficient in the national standard, and gave a relatively certain value. The checking calculation of the actual project is basically consistent with the pullback results and can be used as the subsequent pullback force calculation [20]. However, compared with the checking calculation model proposed by Ashkan et al., the calculation model proposed in this study has higher accuracy.

For the borehole with a specific diameter, the step may have limit curvature radius or limit height, causing excessive pushing stress applied on the pipeline. The stress might exceed the yield strength of the pipe or cause so large backpulling load that exceeds the maximum tensile force capacity of the drilling machine. Therefore, the limit curvature radius and limit height of the step must be considered for safe backpulling of the pipeline. Therefore, we first analyze the 


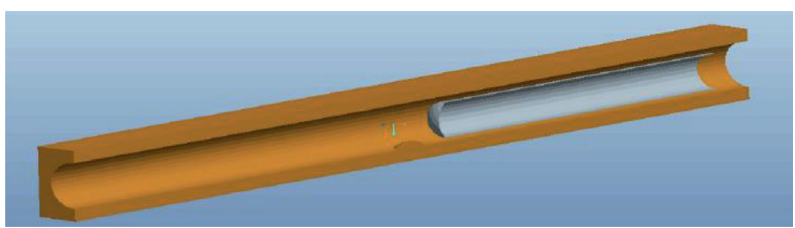

(a)

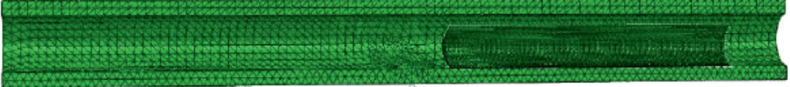

(b)

Figure 3: Simplified model and meshing diagram of stepped hole crossing.

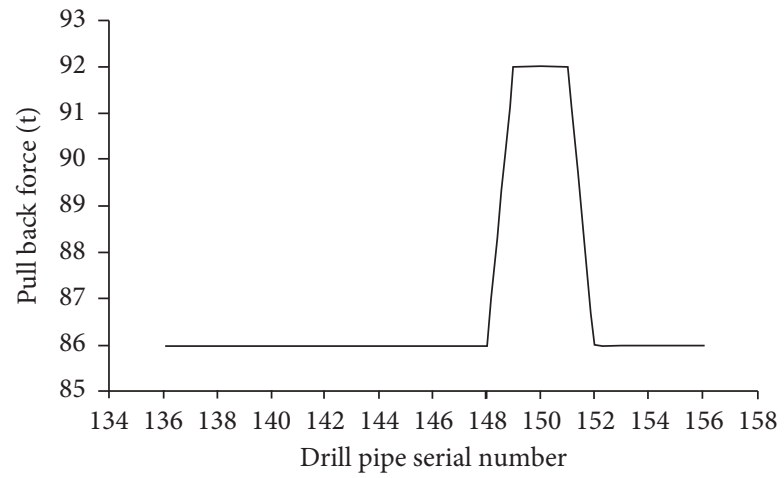

(a)

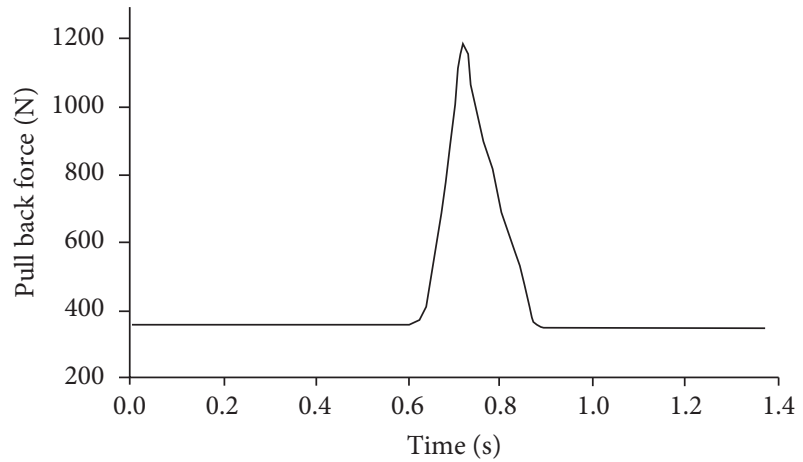

(b)

Figure 4: Comparison of engineering value and calculation result.

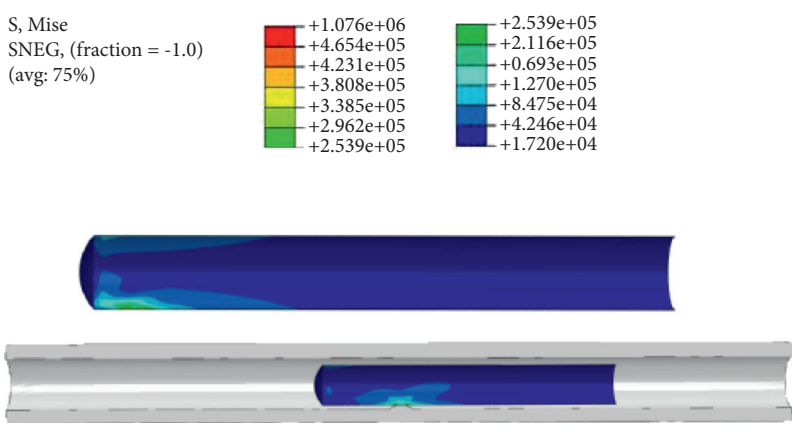

(a)
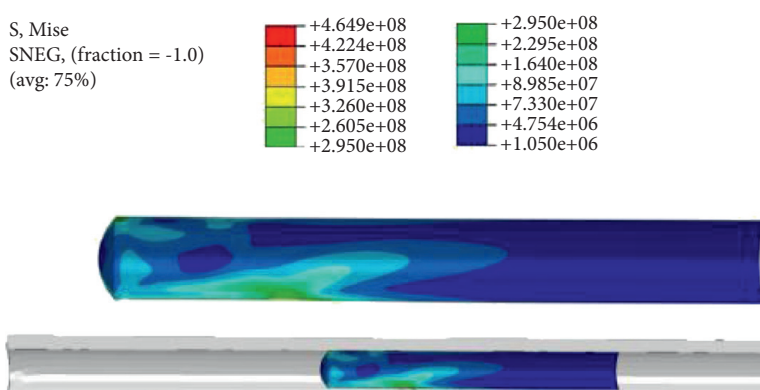

(c)
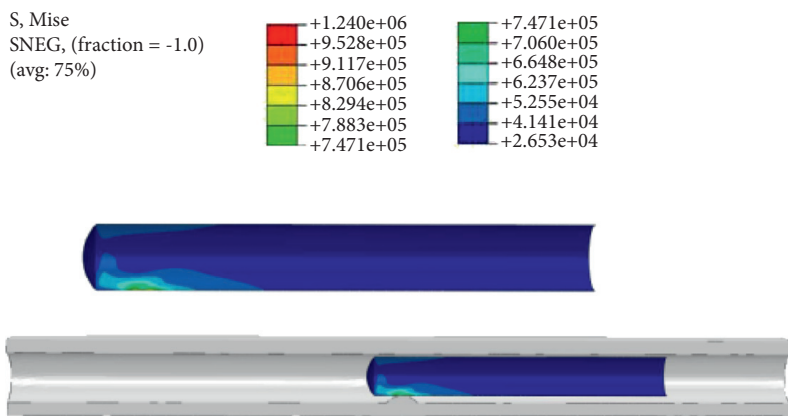

(b)
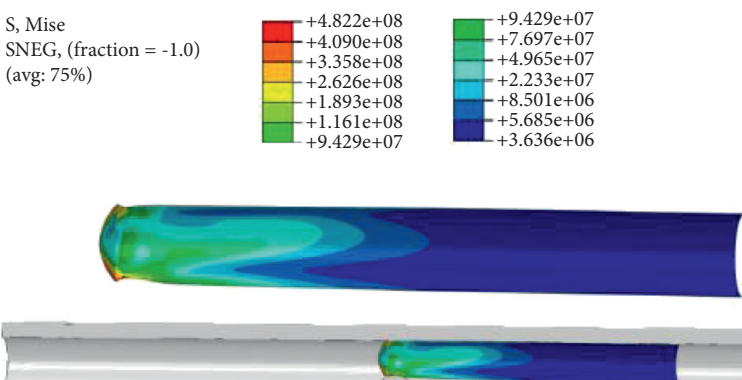

(d)

FIGURE 5: Contact stress distribution in borehole at different step heights.

influence of the step height on the pullback force by setting a constant curvature $r$ of $0.5 \mathrm{~m}$ while changing the heights between $0.1 \mathrm{~m}$ and $0.4 \mathrm{~m}$. The obtained Mises stress distribution is shown in Figure 5.
It can be seen from Figure 5 that when the height of the step increases, the contact stress of the pipe will gradually increase after the pipe hits the step. When the step height is $0.3 \mathrm{~m}$, once hitting happens, the resulting contact stress is up 


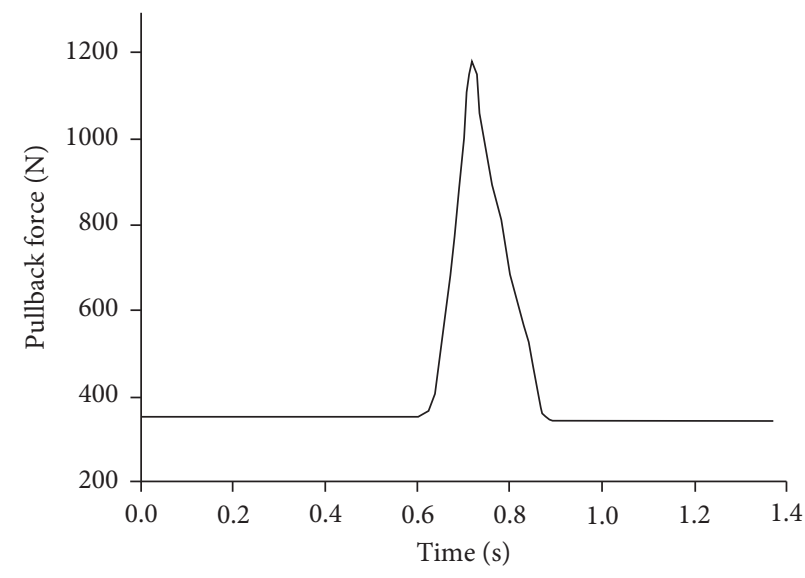

(a)

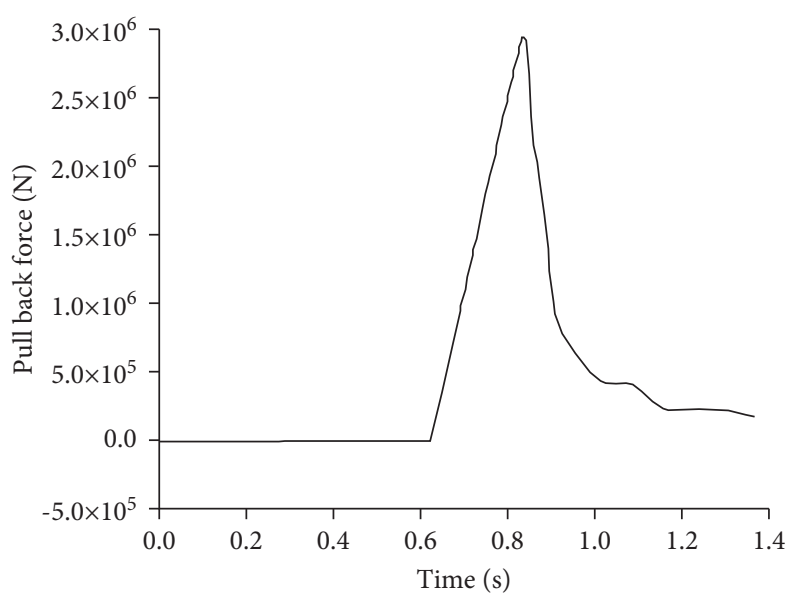

(c)

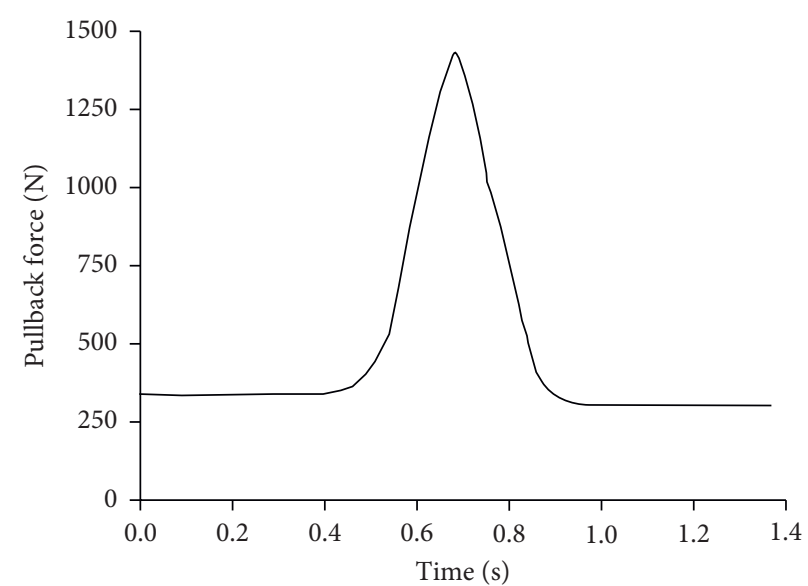

(b)

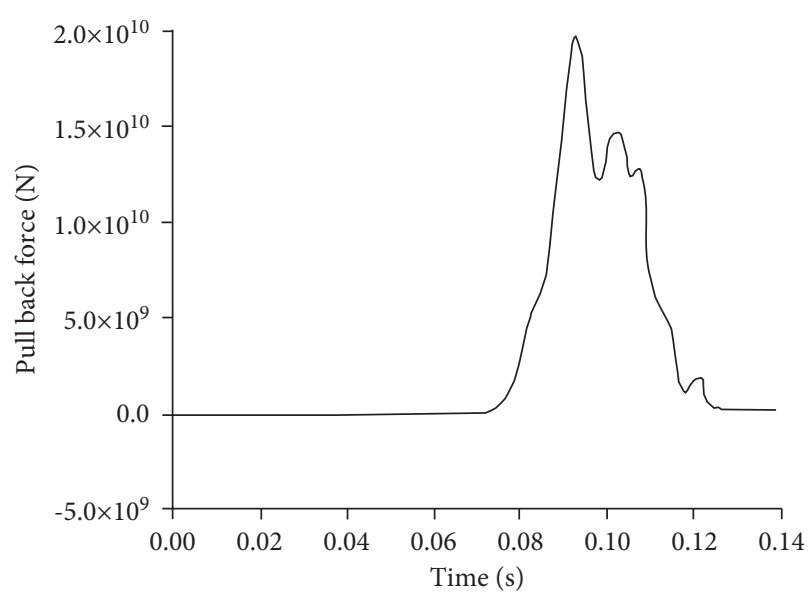

(d)

FIgURE 6: Change curve of pullback force.

to $4.65 \times 108 \mathrm{~Pa}$, higher than the yield stress $(4.2 \times 108 \mathrm{~Pa})$ of the pipeline, so the plastic strain occurs. When the step height is $0.4 \mathrm{~m}$, the plastic strain occurs after the pipe hits the step, causing the pipeline damage. Figure 6 shows the relationship between the height of the step and the pullback force. It can be seen from the figure that the back drag force of the pipe increases suddenly after it just enters the step, and the back drag force after the pipe head passes through the step will decrease rapidly.

The relationship between the maximum contact stress, pullback force, and step height is shown in Figure 7. It can be seen from Figure 7 that with the increase of the step height, the pullback force and the maximum contact stress become larger. For example, when the height is $0.3 \mathrm{~m}$, the stress on the pipeline is higher than the yield limit, resulting in the deformation and damage to the pipeline. In addition, when the height is greater than $0.2 \mathrm{~m}$, the pullback force increases rapidly. Furthermore, when the height is $0.4 \mathrm{~m}$, the pullback force will be higher than the maximum tensile capacity of the current drilling rig.

When the height of the step is $0.2 \mathrm{~m}$, the stress distribution of the pipeline under the curvature radius of $1 \mathrm{~m}$, $0.8 \mathrm{~m}$, and $0.5 \mathrm{~m}$ is shown in Figure 8. It can be seen from

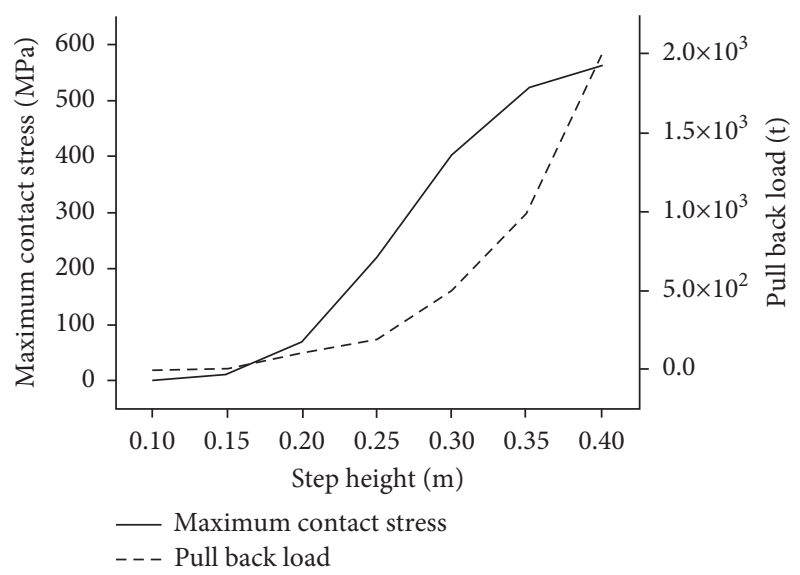

FIgURE 7: Relationship between step height, pullback force, and contact stress.

the figure that there is a minor effect of the step's curvature change on the pipe stress. The corresponding pullback forces are also presented in Figures 9(a) to 9(c), which show high level of similarities under the three curvatures. 


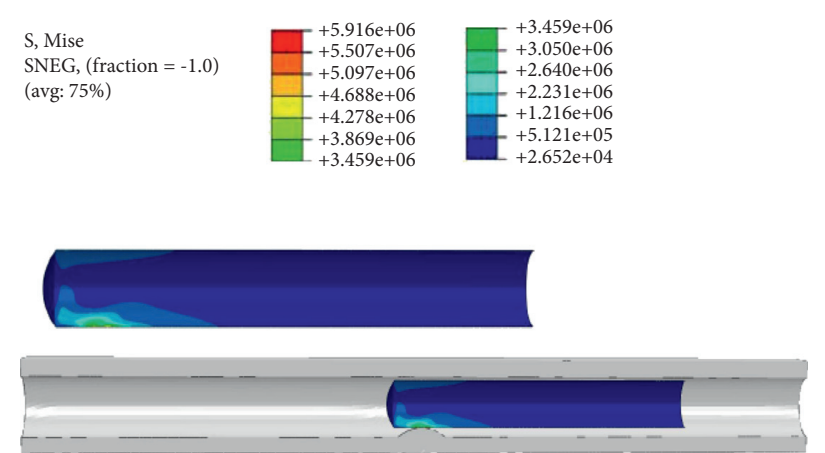

(a)
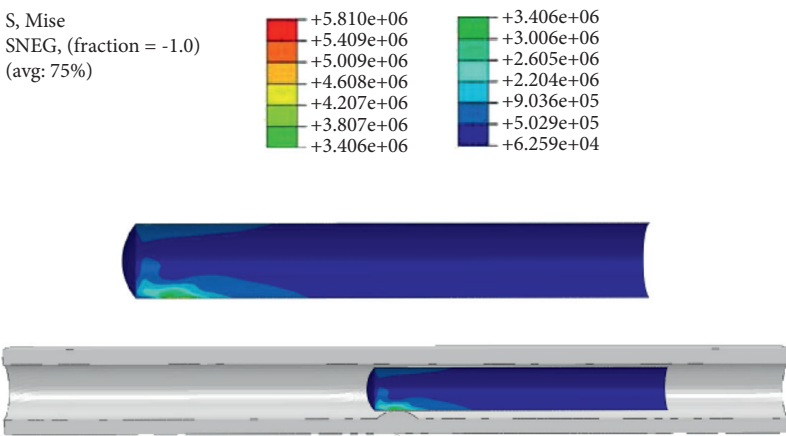

(b)

S, Mise

SNEG, $($ fraction $=-1.0)$

(avg: 75\%)

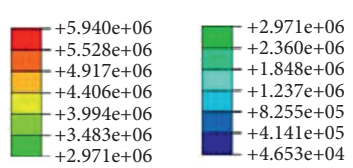

$+4.653 \mathrm{e}+04$

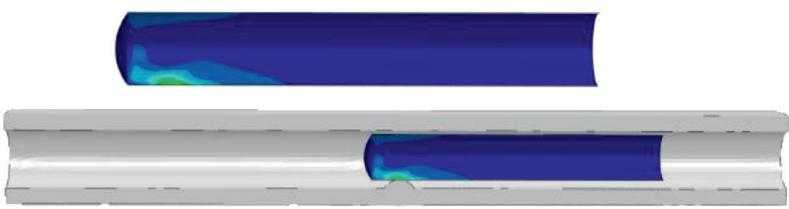

(c)

FIGURE 8: Stress diagram under different radius of curvature.

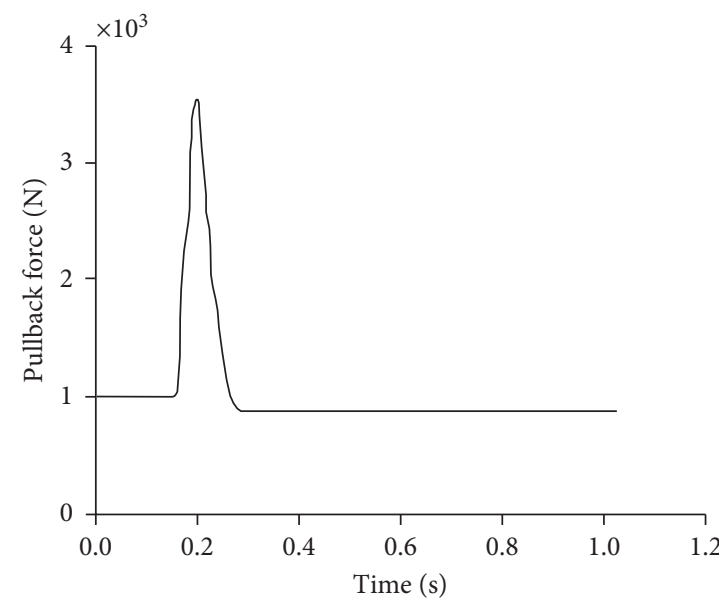

(a)

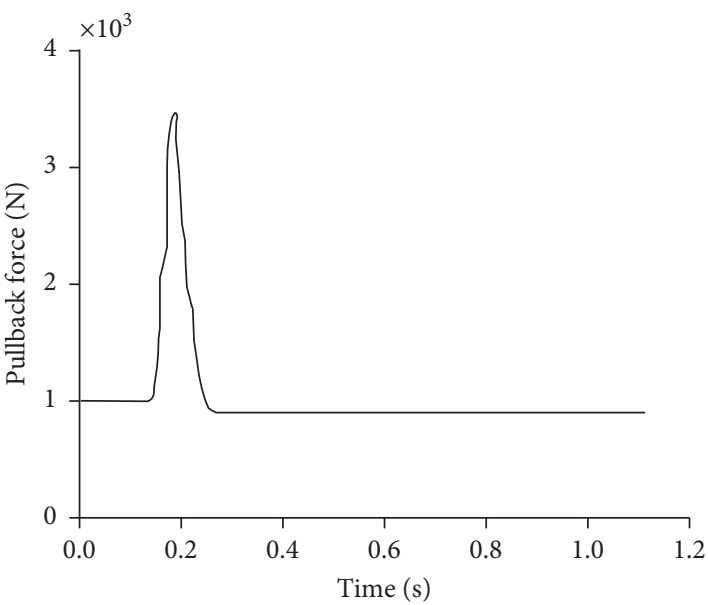

(b)

FIgURE 9: Continued. 


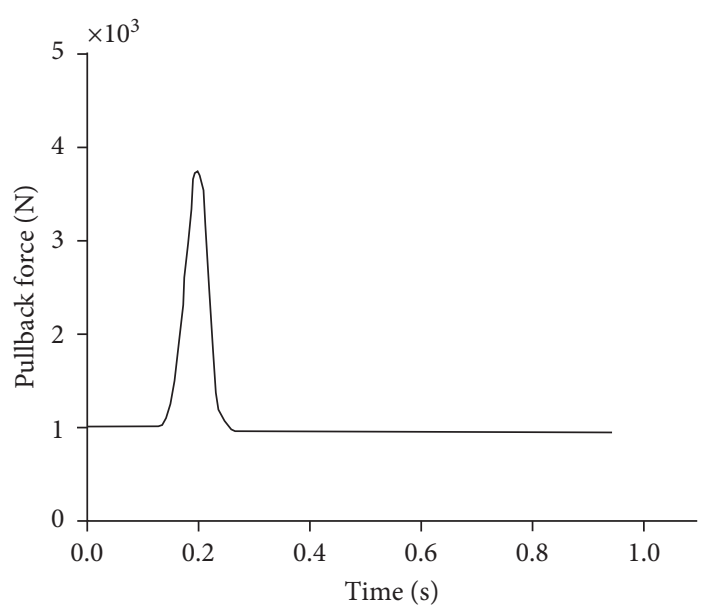

(c)

FIGURE 9: Variation curves of pullback forces under different radiuses of curvature.

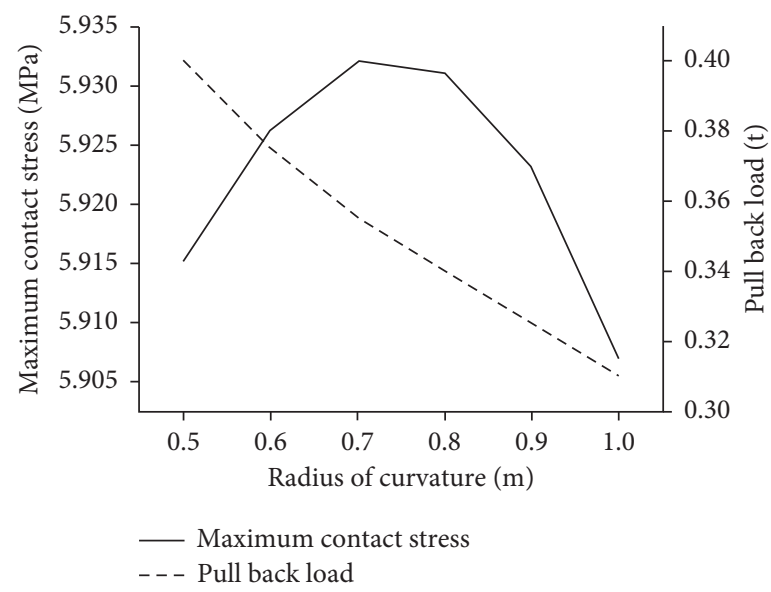

FIGURE 10: Relationship between curvature radius, pullback force, and contact stress.

The relationship between the maximum contact stress, pullback force, and curvature radius of the steps is shown in Figure 10. It shows that for a given step height, the curvature radius is inversely proportional to the step resistance, while the contact stress increases first and then decreases. Nevertheless, such changes in contact stress are minor and can be ignored.

\section{Conclusion}

With the rapid development of the economy and the enhancement of people's awareness of environmental protection, the traditional pipeline laying and excavation technology has long been unable to meet people's needs. Horizontal directional drilling technology has developed rapidly with its advantages of environmental protection, small disturbance, and high efficiency, but its theoretical level is far from meeting the needs of practical engineering, and it needs to be determined according to experience in many cases. Due to the influence of human subjective factors, it is necessary to study the backhauling process of horizontal directional drilling pipeline. This study adopts analytical analysis and numerical simulation to study the pullback force of the trenchless horizontal directional drilling (HDD) pipeline. The results show the following:

(1) When the step height is $0.3 \mathrm{~m}$, the contact stress $\left(4.65 \times 10^{8} \mathrm{~Pa}\right)$ is higher than the yield stress $\left(4.2 \times 10^{8} \mathrm{~Pa}\right)$, leading to the plastic strain; when the step height is $0.4 \mathrm{~m}$, the plastic strain damage to the pipeline occurs.

(2) When the pipe just enters the step, the pullback force increases suddenly and then decreases rapidly after the pipe head passes the step; with the increase of the step height, the plastic strain damage occurs. When the height is higher than $0.2 \mathrm{~m}$, the pullback force increases rapidly.

(3) When the height is $0.4 \mathrm{~m}$, the pullback force will be higher than the maximum pulling force provided by the current drilling rig. Moreover, when the step height is $0.2 \mathrm{~m}$, the influence of step curvature on pipeline stress is small, and the change of pullback force is almost the same under three curvatures. 
(4) When the step height remains unchanged, the curvature radius is inversely proportional to the step resistance, while the contact stress increases first and then decreases with a minor change. During the pullback process, the pipeline will encounter step resistance through the soft and hard staggered stratum, which will suddenly increase the increment of pipeline pullback force and lead to engineering accidents.

At present, the research on pipeline pullback force at home and abroad is mainly focused on the overall level, and there is less research on local areas. Through the common working conditions in the pullback process, the stress state and the change trend of pullback force during pipeline crossing steps are analyzed. If the pullback load suddenly increases and then decreases, it may encounter similar pipeline collision accidents. At the same time, emergency measures can be taken to prevent the crossing accident and ensure the safe pullback of the pipeline.

Due to the limited time and capacity, although the winch effect is considered, the influence of pipe bending on pullback load is not analyzed in this paper. There is no corresponding formula for crossing a variety of strata in complex sections. Although there are many calculation models at present, the calculation results deviate greatly from the actual values. In this paper, there is little research on complex formation, and the understanding of related drilling tools needs to be further deepened. In the future work, we should continue to carry out research in this regard.

\section{Data Availability}

All data generated or analyzed during this study are included within this article.

\section{Conflicts of Interest}

The authors declare no conflicts of interest.

\section{Authors' Contributions}

X. L. analyzed the calculation results and wrote the article; D. H. processed the data; Y. L. and Y. Z. provided the information of the construction site; L. J. and X. Y. offered useful suggestions for the preparation and writing of the paper.

\section{Acknowledgments}

This research was funded by the National Natural Science Foundation of China (No. 51678226), the Natural Science Foundation of Hunan (Nos. 2021JJ50147, 2021JJ30078, and 2019JJ50030), the Scientific Research Project of Education Department of Hunan Province (No. 19C0358), and the Science and Technology Innovation Project of Yiyang City (Nos. 2020YR02 and 2019YR02).

\section{References}

[1] L. Cai and M. A. Polak, "A theoretical solution to predict pulling forces in horizontal directional drilling installations," Tunnelling and Underground Space Technology, vol. 83, pp. 313-323, 2019.

[2] M. Rabiei, Y. Yi, and A. Bayat, "Simple methods for fluidic drag estimation during pipe installation via HDD," Tunnelling and Underground Space Technology, vol. 76, pp. 172-176, 2018.

[3] R. Carpenter, "HDD market growing, but challenges abound," Underground Construction, vol. 73, no. 6, pp. 16-25, 2018.

[4] B. Shu and B. Ma, "The return of drilling fluid in large diameter horizontal directional drilling boreholes - sciencedirect," Tunnelling \& Underground Space Technology Incorporating Trenchless Technology Research, vol. 52, pp. 1-11, 2016.

[5] A. Faghih, Y. Yi, A. Bayat, and M. Osbak, "Efficient drilling in horizontal directional drilling by implementing the concept of specific energy," Geomechanics and Geoengineering, vol. 12, no. 3, pp. 201-206, 2017.

[6] G. Ehm, "The changing pipeline industry," Pipes and Pipelines International, no. 27, pp. 20-22, 2016.

[7] M. S. Mohd Norizam, H. Nuzul Azam, S. Helmi Zulhaidi, A. A. Aziz, and A. Nadzrol Fadzilah, "Literature review of the benefits and obstacle of horizontal directional drilling," IOP Conference Series: Materials Science and Engineering, vol. 271, Article ID 012094, 2017.

[8] C. Schmermund, "2016 Large directional drilling rig census," Pipeline and Gas Journal, vol. 243, no. 10, pp. 64-68, 2016.

[9] J. Griffin, "Mud motor for mid-range HDD rigs," Underground Construction, vol. 74, no. 1, p. 32, 2019.

[10] L. Cai, G. Xu, M. A. Polak, and M. Knight, "Horizontal directional drilling pulling forces prediction methods - a critical review," Tunnelling and Underground Space Technology, vol. 69, pp. 85-93, 2017.

[11] X. Zhu and Q. Yi, "Research and application of reaming subsidence control in horizontal directional drilling," Tunnelling and Underground Space Technology, vol. 75, pp. 1-10, 2018.

[12] A. G. Chehab and I. D. Moore, "Parametric study examining the short and long term response of HDPE pipes when installed by horizontal directional drilling," Tunnelling and Underground Space Technology, vol. 25, no. 6, pp. 782-794, 2010.

[13] J. Griffin, "Solving a puzzling project," Underground Construction, vol. 74, no. 1, pp. 30-31, 2019.

[14] X. Guangli, L. Cai, R. Ji, and Z. Wang, "Numerical simulation of pipe-soil interaction during pulling back phase in horizontal directional drilling installations," Tunnelling and Underground Space Technology, vol. 76, pp. 194-201, 2018.

[15] S. Pinghe, M. Dingqiang, T. A. Samuel, C. Han, and Z. Pengfei, "Laboratory study of fluid properties owing to cutting intrusions during horizontal directional drilling," Underground Space, vol. 5, no. 1, pp. 20-29, 2020.

[16] J. Wang, X. Liu, and S. Wang, "Application of directional drilling forward pushing process to crossing mountain with large drop," Gas \& Heat, vol. 37, no. 7, pp. 67-70, 2017.

[17] M. Mohammadi, J. G. Dai, Y. F. Wu, and Y. L. Bai, "Development of extended Drucker-Prager model for non-uniform FRP-conflned concrete based on triaxial tests," Construction and Building Materials, vol. 224, no. 10, pp. 1-18, 2019. 
[18] E. M. Hossain, Fundamentals of Drilling Engineering (Multiple Choice Questions And Workout Examples For Beginners And Engineers) || Horizontal And Directional Drilling, Wiley, Hoboken, NJ, USA, 2016.

[19] J. Raclavský, "Theoretical problems of pipe inserting by making use of the method of horizontal directional drilling," Acta Montanistica Slovaca, vol. 13, pp. 156-160, 2008.

[20] F. Ashkan and Anup, "Study on parameters of pipeline construction pullback force in horizontal directional drilling," Trenchless technology, no. 1, pp. 11-14, 2016. 